\title{
Inhibitory Effect of Waste Glass Powder on ASR Expansion Induced by Waste Glass Aggregate
}

\author{
Shuhua Liu ${ }^{1,2, *}$, Shu Wang ${ }^{1,3}$, Wan Tang ${ }^{1}$, Ningning $\mathrm{Hu}^{1}$ and Jianpeng Wei ${ }^{1}$ \\ Received: 18 July 2015 ; Accepted: 28 September 2015 ; Published: 9 October 2015 \\ Academic Editor: Prabir Sarker \\ 1 State Key Laboratory of Water Resources and Hydropower Engineering Science, Wuhan University, \\ Wuhan 430072, China; wangshu@whu.edu.cn (S.W.); tangwan@whu.edu.cn (W.T.); \\ huningning@whu.edu.cn (N.H.); weijianpeng@whu.edu.cn (J.W.) \\ 2 Department of Civil, Environmental and Geomatic Engineering, University College London, \\ Gower Street, London WC1E 6BT, UK \\ 3 China Construction Ready Mixed Concrete Co., Ltd., Wuhan 430074, China \\ * Correspondence: shliu@whu.edu.cn; Tel.: +86-27-6877-2233; Fax: +86-27-6877-2310
}

\begin{abstract}
Detailed research is carried out to ascertain the inhibitory effect of waste glass powder (WGP) on alkali-silica reaction (ASR) expansion induced by waste glass aggregate in this paper. The alkali reactivity of waste glass aggregate is examined by two methods in accordance with the China Test Code SL352-2006. The potential of WGP to control the ASR expansion is determined in terms of mean diameter, specific surface area, content of WGP and curing temperature. Two mathematical models are developed to estimate the inhibitory efficiency of WGP. These studies show that there is ASR risk with an ASR expansion rate over $0.2 \%$ when the sand contains more than $30 \%$ glass aggregate. However, WGP can effectively control the ASR expansion and inhibit the expansion rate induced by the glass aggregate to be under $0.1 \%$. The two mathematical models have good simulation results, which can be used to evaluate the inhibitory effect of WGP on ASR risk.
\end{abstract}

Keywords: glass powder; glass aggregate; alkali-silica reaction (ASR); inhibitory effect

\section{Introduction}

Since the 1980s, the use of waste glass (WG) in concrete has been investigated in USA and Europe. With regard to concrete production, WG can be used as fine aggregate to replace sand after being crushed or as a supplementary cementitious material to replace cement after being ground. In the former case, glass exhibits double effects on properties of concrete, both positive and negative. If the replacement ratio is greater than $20 \%-30 \%$, the mechanical properties will decrease as the replacement ratio increases [1]. However, the glass can effectively reduce the porosity of concrete [2,3] so as to improve the strength [4] and durability [5] if its replacement ratio is below $20 \%-30 \%$. In the latter case, waste glass powder (WGP) can participate in pozzolanic reaction [6], which is beneficial to the properties of the binder. But the research on WG concrete is still at the preliminary stage [4] and needs further study.

WG contains a significant amount of alkali and silicon dioxide (reactive silica). It may lead to alkali-silica reaction (ASR) risk and concrete cracking, which is the main reason accounting for the early stagnation of research on the use of WG in concrete. Lots of research [1-3,6] indicates that WG may cause ASR expansion risk in concrete. However, most research has been conducted at the macro level, the micro aspects and the interface properties of the WG aggregate have drawn little attention, so is its inhibitory effect. Meanwhile, WGP can be used as a supplementary cementitious material, it has pozzolanic activity, and it can improve the strength of the cementitious system [7,8]. WGP seldom relates with ASR. The chemical reaction mechanism of WGP in concrete is still not well understood. 
The effect mechanism of WG aggregate and WGP on concrete still needs confirmation. Chemical reaction model and ASR risk of WGP under alkaline environment also need to be established. Only when the ASR mechanism of WG in concrete is fully understood, is it possible to take full advantage of WG and provide theoretic support for its wide application.

In this paper, ASR expansion and its mechanism of mortar containing WG as fine aggregate are investigated. The inhibitory effect of WGP as a replacement of cement on ASR is studied and verified by macro and micro tests. In addition, the results refer to used green glass, which is a soda-lime glass. Even slight changes in the compositions (white glass, brown glass, or others) could possibly lead to somewhat different results. The micro properties are also tested by scanning electron microscopy (SEM), which can be used to explain the ASR mechanism in depth.

\section{Experimental}

\subsection{Raw Materials}

Raw materials used in this paper include cement, glass, water and standard sand. The cement is 42.5 Portland cement, whose chemical compositions are listed in Table 1.

Soda-lime glass is employed in this work due to its popularity all over the world. WG aggregate is prepared by collected green glass after being cleaned, dried, crushed, and taken for a screening test according to GB/T14684-2001 Sand for construction [9]. The mass content of all sizes is listed in Table 2. The smaller particles $(0.16-0.315 \mathrm{~mm})$ occupy a certain proportion, i.e., $15 \%$.

Table 1. Chemical compositions of cement and glass (mass, \%).

\begin{tabular}{ccccccccc}
\hline Compositions & $\mathrm{SiO}_{2}$ & $\mathrm{Al}_{2} \mathrm{O}_{3}$ & $\mathrm{CaO}$ & $\mathrm{Fe}_{2} \mathrm{O}_{3}$ & $\mathrm{MgO}$ & $\mathrm{BaO}$ & $\mathrm{F}$ & $\mathrm{SO}_{3}$ \\
\hline cement & 21.25 & 2.91 & 63.09 & 3.24 & 0.68 & - & - & 3.36 \\
glass & 68.41 & 2.58 & 9.52 & 0.39 & 0.39 & 0.50 & 0.30 & 0.13 \\
\hline Compositions & $\mathrm{K}_{2} \mathrm{O}$ & $\mathrm{Na}_{2} \mathrm{O}$ & $\mathrm{TiO}_{2}$ & $\mathrm{MnO}$ & $\mathrm{P}_{2} \mathrm{O}_{5}$ & $\mathrm{Cr}_{2} \mathrm{O}_{3}$ & $\mathrm{ZnO}$ & $\mathrm{Loss}$ \\
\hline cement & 1.12 & 0.31 & 0.31 & 0.04 & 0.17 & - & - & 3.52 \\
glass & 2.14 & 14.10 & 0.11 & 0.31 & 0.07 & 0.12 & 0.89 & 0.04 \\
\hline
\end{tabular}

Table 2. Gradation of glass aggregate.

\begin{tabular}{lccccc}
\hline Sieve Diameter $(\mathbf{m m})$ & $5-2.5$ & $2.5-1.25$ & $1.25-0.63$ & $0.63-0.315$ & $0.315-0.16$ \\
\hline Mass percentage (\%) & 10 & 25 & 25 & 25 & 15 \\
\hline
\end{tabular}

WGP refers to the glass particles with a maximum particle size below $300 \mu \mathrm{m}$ in this work. WGP is prepared by grinding the WG fine aggregate in ball mill. Furthermore, WGP is divided into seven finenesses, named GA, GB, GC, GD, GE, GF and GG by controlling the grinding time. Its chemical compositions are also presented in Table 1 . The main chemical compositions are $68.41 \% \mathrm{SiO}_{2}, 14.10 \%$ $\mathrm{Na}_{2} \mathrm{O}$ and $10.52 \% \mathrm{CaO}$, and it is a typical soda-lime glass $\left(71 \% \mathrm{SiO}_{2}, 13 \%-15 \% \mathrm{Na}_{2} \mathrm{O}\right.$ and $\left.10 \% \mathrm{CaO}\right)$. WGP may have pozzolanic activity even cementing property due to high lime and silicon content. Meanwhile, it may also raise ASR risk of concrete due to the high alkali and silicon content.

Figure 1 shows the particle size distribution of the seven WGPs and cement. The seven WGPs become finer in turn. The gradation of GA and GB has larger leap and lacks particles with certain size, i.e., 300-500 $\mu \mathrm{m}$ and 200-400 $\mu \mathrm{m}$, respectively. The size distribution of GC is similar to that of GD. The particle size distribution of GE, GF and GG are similar to that of cement. No cement particle is larger than $100 \mu \mathrm{m}$, while the three WGPs contain small amounts of particles with a size higher than $100 \mu \mathrm{m}$. Furthermore, the specific surface area of the three WGPs is greater than that of cement because specific surface area depends on both particle size and particle shape of WGP. WGP contains more slender angular particles due to its fragile features, which leads to a higher specific surface area. 
Compared with cement, GF and GG have more particles below $20 \mu \mathrm{m}$ and fewer particles with the size over $30 \mu \mathrm{m}$.

The density of WGP is about $2.5 \mathrm{~g} / \mathrm{cm}^{3}$ (Table 3), which is less than that of cement (about $3.1 \mathrm{~g} / \mathrm{cm}^{3}$ ). The particle morphology of WGP is shown in Figure 2. The surface of WGP particles is relatively smooth, and its shape is irregularly angular. WGP particle size is consistent with the above analysis: the coarsest is GA, while the finest is GG.

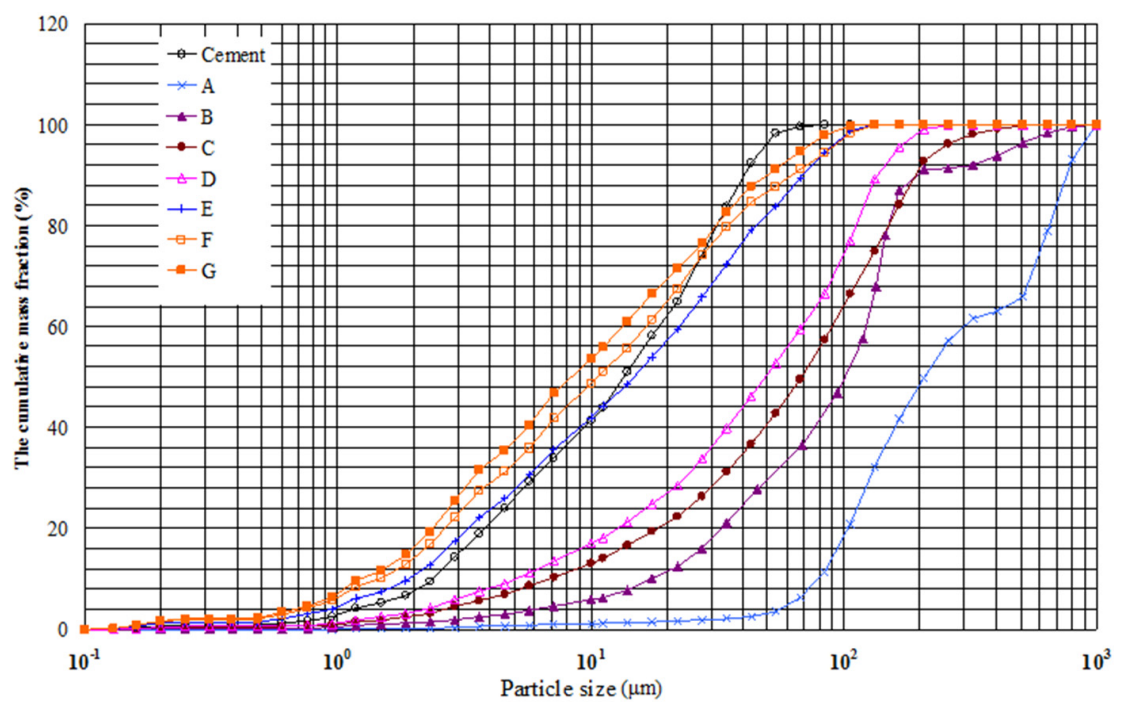

Figure 1. Particle size distribution of cement and the seven waste glass powders (WGPs).

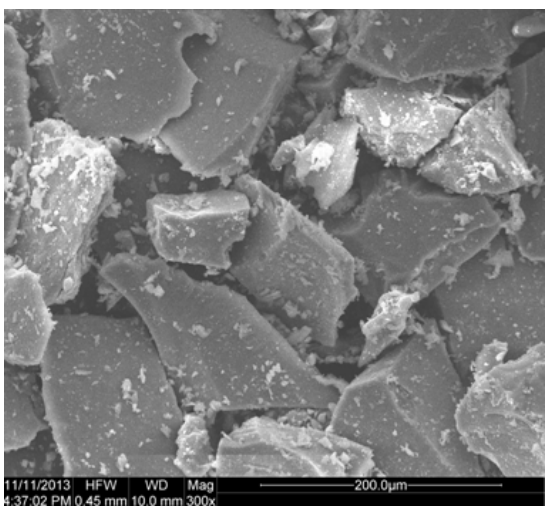

(a)

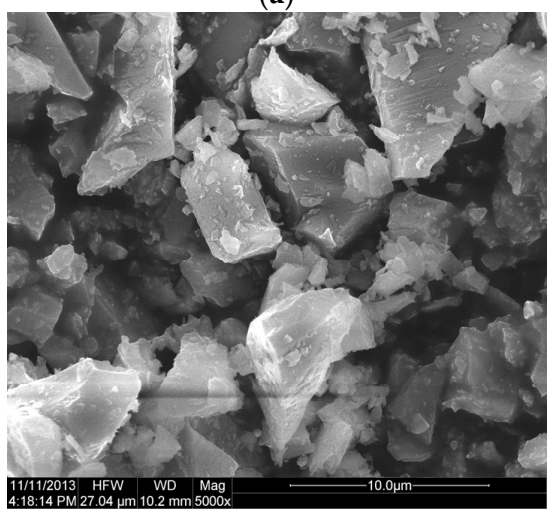

(c)

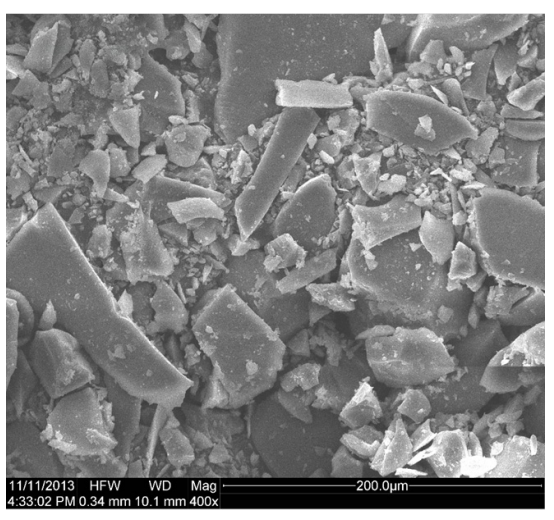

(b)

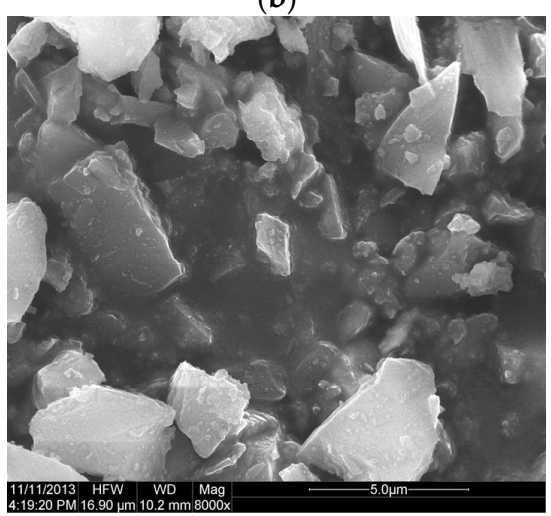

(d)

Figure 2. Particle morphology of WGPs: (a) GA, (b) GB, (c) GE and (d) GG. 
Table 3. Physical characteristics of the seven waste glass powders (WGPs).

\begin{tabular}{cccccc}
\hline Samples & $\begin{array}{c}\text { Average Particle Size } \\
(\boldsymbol{\mu \mathbf { m } )}\end{array}$ & $\begin{array}{c}\text { Specific Surface Area } \\
\mathbf{( m}^{\mathbf{2} / \mathbf{k g})}\end{array}$ & $\begin{array}{c}\geqslant \mathbf{6 5} \boldsymbol{\mu \mathbf { m }} \\
\mathbf{( \% )}\end{array}$ & $\begin{array}{c}\geqslant \mathbf{8 0} \boldsymbol{\mu \mathbf { m }} \\
\mathbf{( \% )}\end{array}$ & $\begin{array}{c}\text { Density } \\
\left(\mathbf{g} / \mathbf{c m}^{\mathbf{3}} \mathbf{)}\right.\end{array}$ \\
\hline GA & 209.2 & 31.00 & 94.33 & 89.97 & 2.48 \\
GB & 111.1 & 121.00 & 55.06 & 45.05 & 2.53 \\
GC & 68.29 & 217.00 & 51.58 & 44.53 & 2.49 \\
GD & 49.08 & 289.00 & 37.09 & 30.05 & 2.49 \\
GE & 14.94 & 658.00 & 11.55 & 6.63 & 2.49 \\
GF & 10.64 & 837.00 & 9.37 & 6.55 & 2.50 \\
GG & 8.20 & 903.00 & 5.92 & 2.75 & 2.48 \\
\hline
\end{tabular}

As can be seen from Figure 3, the X-ray diffraction (XRD) pattern of WGP is dispersive and exhibits a wide diffraction peak, named "bread peak", near $25^{\circ}$ different from the sharp peak of crystal, which indicates WGP is almost amorphous. WGP has great activity theoretically, and it is also related to its chemical construction, i.e., the amorphous silica.

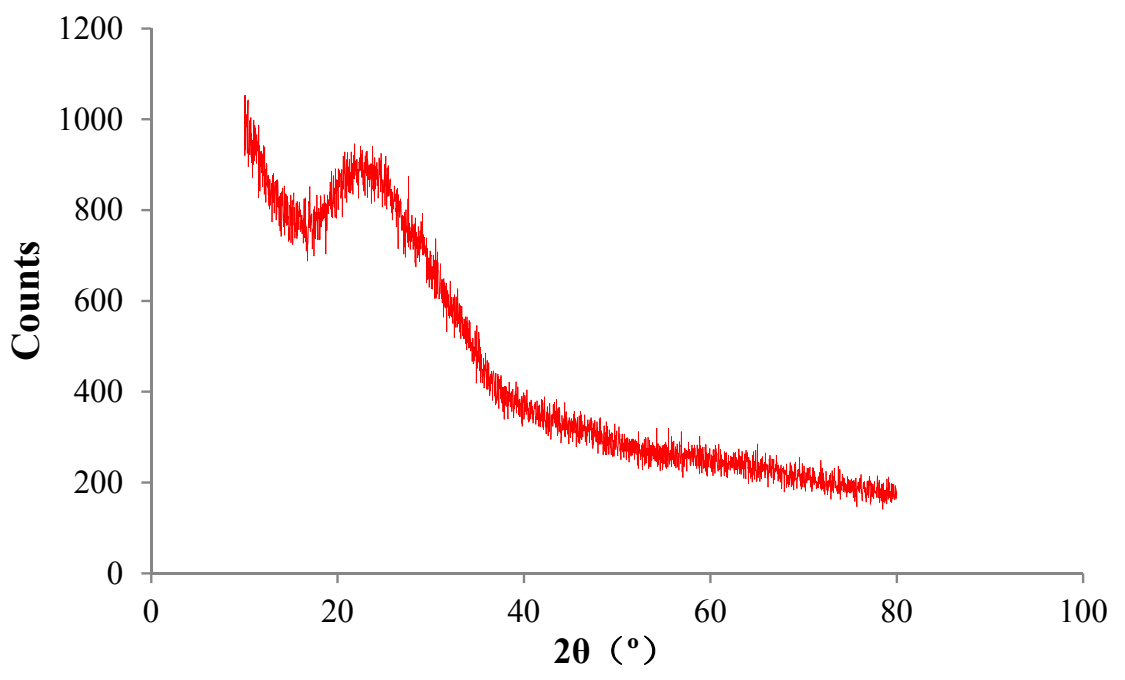

Figure 3. X-ray diffraction (XRD) pattern of WGP.

\subsection{Experiments}

In order to study the ASR activity and expansion development induced by WG aggregate, the mortar bar method (equivalent to ASTM C227 [10]) and the accelerated mortar bar method (equivalent to ASTM C1260 [11]) are used. The alkali content of cement is adjusted to be $0.6 \%$. Mortars with water to cementitious materials ratio of 0.47 are prepared whose size is $25.4 \times 25.4 \times 285 \mathrm{~mm}^{3}$. The mix proportions are shown in Table 4 . As for the accelerated mortar bar method, the specimens are demolded after $24 \mathrm{~h}$ and then placed in $1 \mathrm{~N} \mathrm{NaOH}$ solution at $80^{\circ} \mathrm{C}$ to be totally immersed for $3,7,14$ and 28 days. As for the mortar bar method, the specimens are demolded after $24 \mathrm{~h}$ and then stored in $\mathrm{NaOH}$ solution at $38{ }^{\circ} \mathrm{C}$ for 2 weeks, 1, 2, 3 and 6 months. According to the accelerated mortar bar method, the expansion rate less than $0.10 \%$ at 14 days is indicative of innocuous behavior, and the expansion rate larger than $0.20 \%$ is indicative of potentially deleterious expansion. According to the mortar bar method, the expansion rate less than $0.10 \%$ at 6 months is indicative of innocuous behavior. Tests are conducted according to regulations for aggregate alkali activity in test code SL352-2006 hydraulic concrete.

After ASR test, small clean specimens are taken out from the central of the mortars by a hammer and soaked in anhydrous ethanol to avoid carbonization before SEM observation, less than two weeks. The samples are dried for $2-3 \mathrm{~h}$ at $60^{\circ} \mathrm{C}$ in a vacuum drying oven and placed in a vacuum coating machine for dehumidifying and gilding treatment. 
Table 4. Mix proportions of mortar.

\begin{tabular}{ccccccc}
\hline Samples & Cement (g) & Glass Powder $(\mathrm{g})$ & Water $(\mathrm{g})$ & Glass Aggregate $(\mathrm{g})$ & Standard Sand $(\mathrm{g})$ & $\mathrm{NaOH}(\mathrm{g})$ \\
\hline *-WGP0 & 400 & 0 & 188 & 810 & 90 & 0.00 \\
*-WGP10 & 360 & 40 & 188 & 810 & 90 & 0.00 \\
*-WGP20 & 320 & 80 & 188 & 810 & 90 & 0.31 \\
*-WGP30 & 280 & 120 & 188 & 810 & 90 & 0.85 \\
\hline
\end{tabular}

Note: Number *, i.e., A, B, C, D, E, F and G, on behalf of the incorporation of glass powder GA, GB, GC, GD, GE, GF, GG, the feature of glass powder GA-GG are corresponding to the glass powder in Table 3.

\section{Results and Discussions}

\subsection{ASR of Glass Aggregate}

The ASR risk of glass aggregate used to replace standard sand is tested by controlling the replacement ratio, i.e., $0 \%, 10 \%, 30 \%, 50 \%, 70 \%, 90 \%$ and $100 \%$, labeled as WG0, WG10, WG30, WG50, WG70, WG90 and WG100.

\subsubsection{The Accelerated Mortar Bar Method}

According to Figure 4, WG aggregate belongs to alkali reactive aggregate. When glass aggregate content is higher than $30 \%$, the expansion rate is larger than $0.10 \%$ at 14 days; when the content increases to $50 \%$, the expansion rate of 14 days exceeds $0.20 \%$; and, as the content increases further, the increasing trend of expansion rate obviously weakens and even decreases.

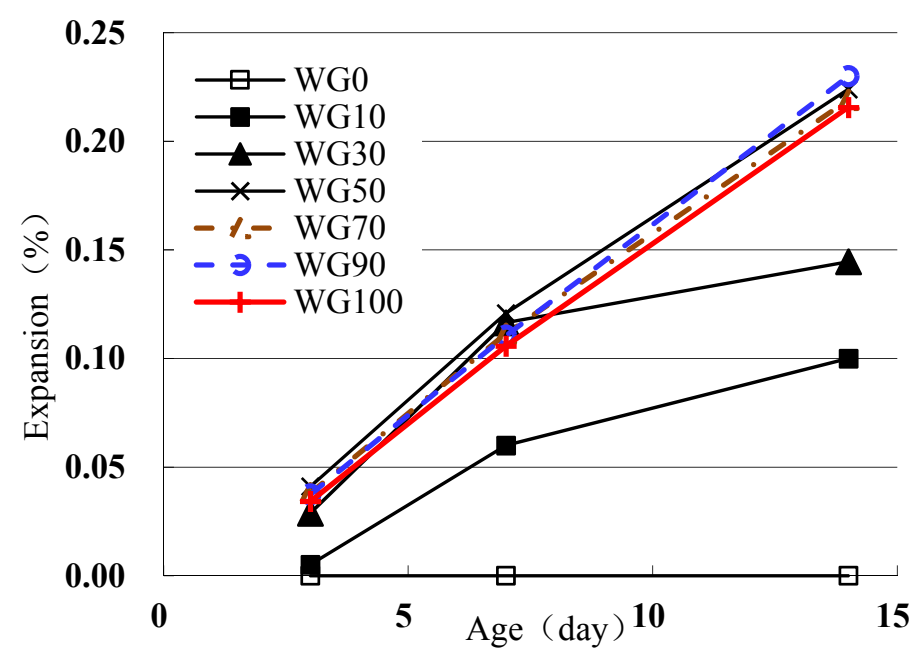

Figure 4. Alkali-silica reaction (ASR) expansion rate of the mortars with waste glass (WG) aggregate of different contents (accelerated mortar bar method).

The expansion of 14 days reaches the maximum when WG content is $90 \%$, which is the worst point for the ASR of concrete [12], but not $100 \%$. When glass aggregate replacement ratio is below $90 \%$, higher replacement ratio means more $\mathrm{SiO}_{2}$ and promotes more ASR gel. When the replacement ratio is higher than $90 \%$, the increasing amount of $\mathrm{SiO}_{2}$ in the pore solution results in more $\mathrm{OH}^{-}$ absorption, which leads to insufficient $\mathrm{OH}^{-}$to participate in ASR locally so that the amount of ASR gel decreases. WG aggregate has five size grades and contains partial WGP, which has inhibitory effect on ASR expansion because of its pozzolanic activity. Thus the expansion of samples containing more glass aggregate is a little lower. While some researchers found that ASR expansion shows increasing trend as glass aggregate replacement ratio increases [13]. This is probably due to the different test conditions, glass and cement types. Most researchers [13-15] have used a replacement ratio less than $50 \%$, which is insufficiently detailed. 


\subsubsection{The Mortar Bar Method}

The mortar bar method is also used and compared with the accelerated mortar bar method. The main difference is the curing temperature. In order to test the ASR activity rapidly, the period of the accelerated mortar bar method is 14 days, and the curing temperature is $80^{\circ} \mathrm{C}$. The temperature of the mortar bar method is $38^{\circ} \mathrm{C}$, which is closer to the actual engineering application [14], and is more reliable $[15,16]$. Figure 5 indicates that WG aggregate causes ASR expansion of the mortars.

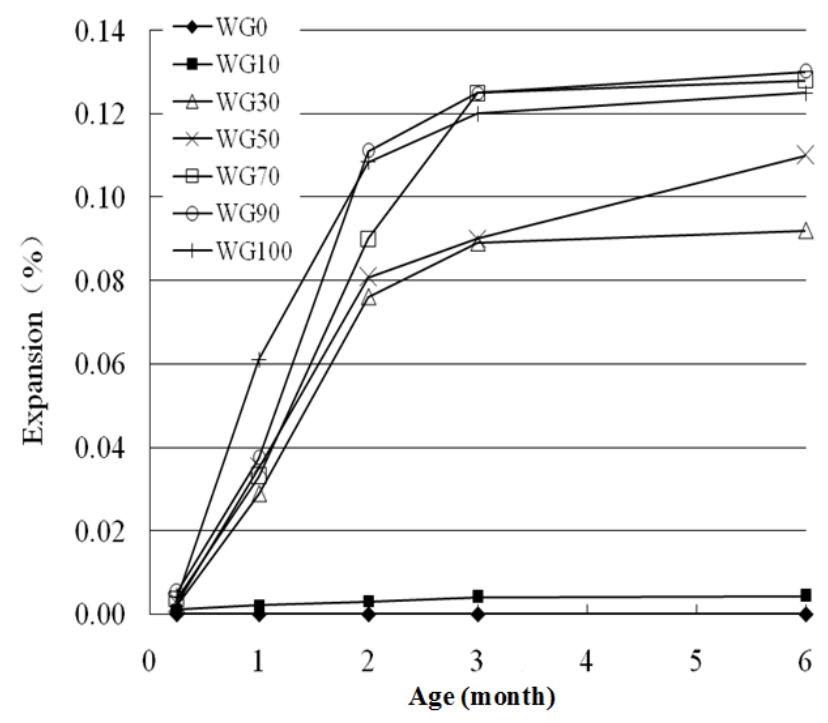

Figure 5. ASR expansion of the mortars with and without WG aggregate (mortar bar method).

As temperature can greatly improve the ASR, ASR expansion of the mortar bar method is much lower than that of the accelerated mortar bar method. When the replacement ratio of glass aggregate is greater than $30 \%$, the expansion is larger than $0.05 \%$ at 90 days; when the replacement ratio increases to $50 \%$ or more, the expansion improves rapidly and reaches the most harmful level at $90 \%$ replacement ratio at 60,90 and 180 days, which verifies the results observed by the accelerated mortar bar method.

\subsection{The Inhibitory Effect of WGP on ASR}

In order to analyze the inhibitory effect of WGP on ASR risk induced by WG aggregate, WGP is used to replace cement. The mix proportions are shown in Table 4.

\subsubsection{Effect of WGP Content}

As shown in Figure 6, the expansion rate of all samples is reduced with the increase of WGP content. Pozzolanic reaction of WGP occurs firstly and $\mathrm{Ca}(\mathrm{OH})_{2}$ in solution is consumed, which leads to the reduction of ASR expansion. Meanwhile, calcium silicate hydrates (C-S-H) produced by WGP's pozzolanic reaction combines with a part of alkali $[17,18]$, which is useful to reduce ASR. The alkali of WGP released to pore solution is little, much lower than that of cement [14], which means the alkali released by the cementitious materials to pore solution reduces with the increase of WGP content. Different WGPs result in different inhibitory effect. For Group A, though the expansion rate is still reduced by WGP, the result is not significant. With respect to Groups B-E, when the content reaches $30 \%$, the expansion can be kept in safe range. Groups $\mathrm{F}$ and $\mathrm{G}$ are able to achieve a high inhibitory effect when WGP content reaches $20 \%$. The difference is related to the characteristics of WGP with different sizes.

The growth of ASR expansion rate is leveling off after mixing WGP, and the time-expansion curve converged gradually, especially for the samples containing $30 \%$ WGP. The pozzolanic activity of WGP is more obvious at later age, so it is more effective for reducing ASR. 


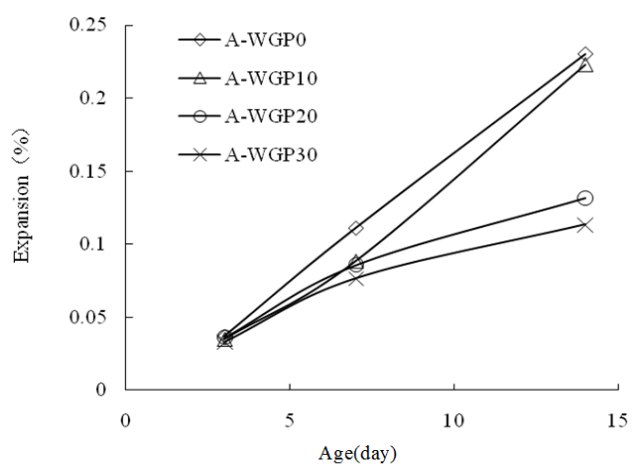

(a)

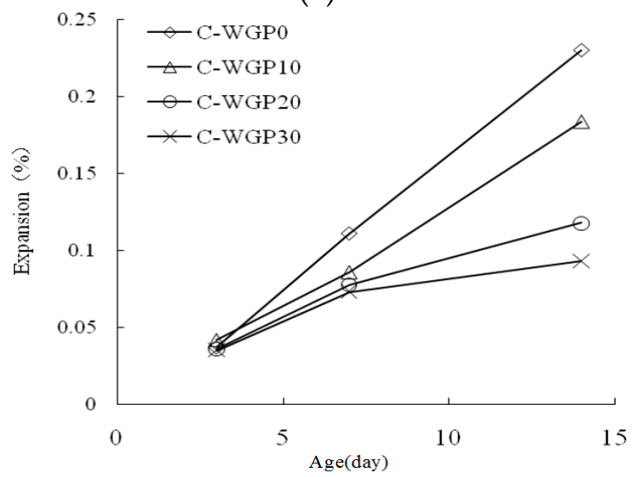

(c)

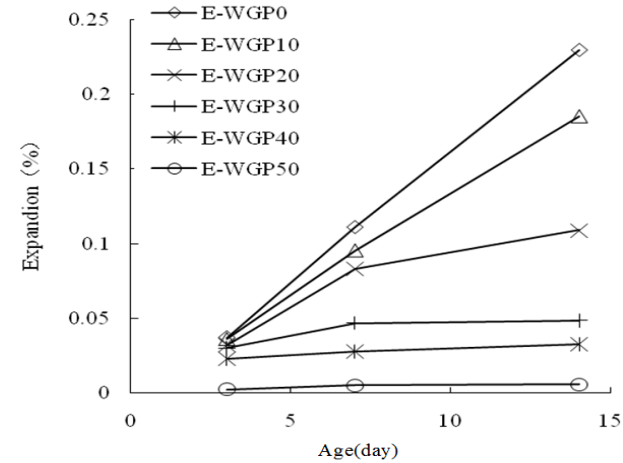

(e)

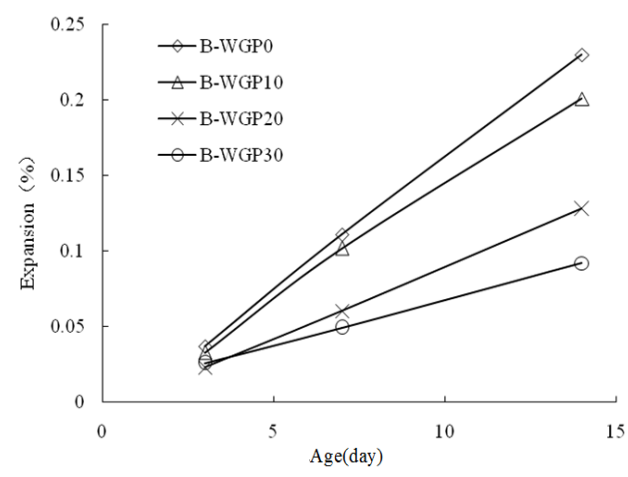

(b)

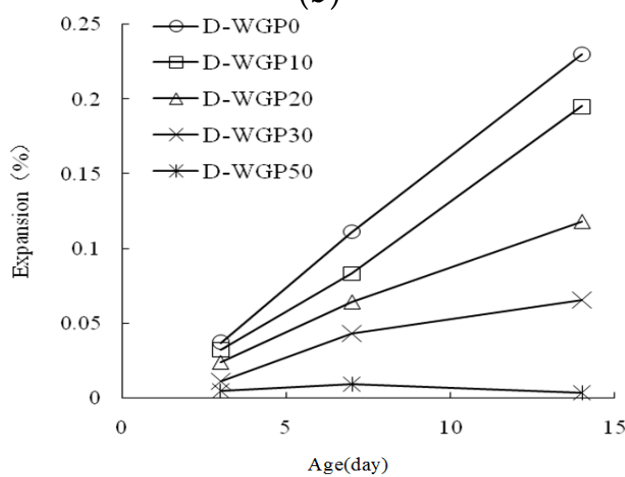

(d)

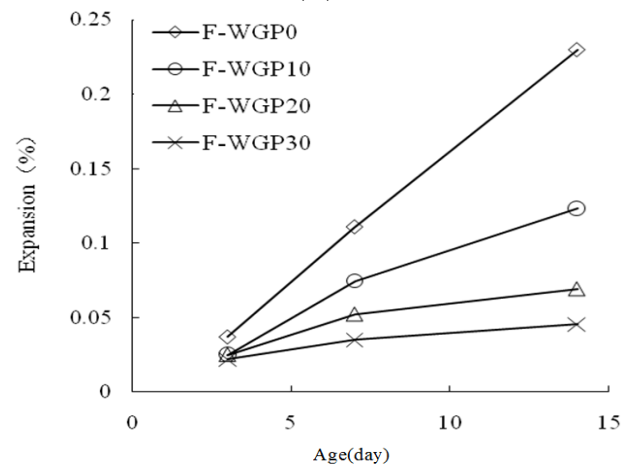

(f)

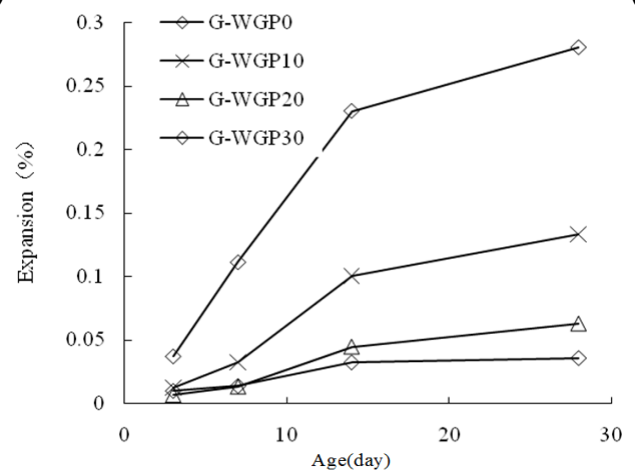

(g)

Figure 6. ASR expansion rate of the mortars containing different WGPs: (a) GA, (b) GB, (c) GC, (d) GD, (e) GE, (f) GF and (g) GG.

\subsubsection{Effect of WGP Particle Size}

The prevailing research shows that ASR expansion will decrease with the reduction of glass particle size when WGP is used as a cement substitute at the same replacement ratio. Recycled 
soda-lime glass aggregate shows the highest expansion in the size range of 1.18-2.36 mm when maintaining the same composition and mineralogy [19]. If the average particle size of WGP is less than $300 \mu \mathrm{m}$, there is no ASR expansion risk [19-22]. Some scholars have concluded that the blizzard ASR expansion does not occur as the average particle size is $0.6-1.18 \mathrm{~mm}$ or less, others argue this critical region is less than $0.15-0.30 \mathrm{~mm}$ [19]. Although there is still ASR expansion when WGP is extremely fine, the expansion rate is very low which has little influence on its use in concrete.

WGP with different particle size used to evaluate its inhibitory effect is shown in Figure 7. The finer the WGP, the higher is its inhibitory effect on ASR expansion [23]. If WGP size is less than $209.2 \mu \mathrm{m}$, it will not cause ASR damage and meanwhile has a certain inhibitory effect. For large WGP particles, $\mathrm{SiO}_{2}$ from the particle surface will be dissolved into the solution and react with $\mathrm{Ca}(\mathrm{OH})_{2}$ to form C-S-H gel until the local depletion. Thereafter, $\mathrm{SiO}_{2}$ react with alkali to generate ASR gel. However, as for fine WGP particles, WGP only conducts pozzolanic reaction and can be completely dissolved. Furthermore, WGP contains higher level of $\mathrm{Ca}^{2+}$, which is released for pozzolanic reaction and involved in the hydrated products [24]. So there may be not enough $\mathrm{SiO}_{2}$ to form ASR gel. And ASR gel swelling caused by WGP, which belongs to the uniform expansion, will not cause local destruction of concrete. The finer WGP has higher pozzolanic activity. The active aggregate is wrapped by WGP particles whose dissolution causes pozzolanic reaction to form $\mathrm{C}-\mathrm{S}-\mathrm{H}$ gel. Then, these small particles of $\mathrm{C}-\mathrm{S}-\mathrm{H}$ gel react with $\mathrm{SiO}_{2}$ of glass again to generate $\mathrm{C}-\mathrm{S}-\mathrm{H}$ gel with low $\mathrm{Ca} / \mathrm{Si}$ ratio. ASR expansion rate can also be controlled in the safe level when the WGP content is $10 \%, 20 \%$ and $30 \%$ with its average particle size less than $8.2,16.95$ and $144.08 \mu \mathrm{m}$, respectively.

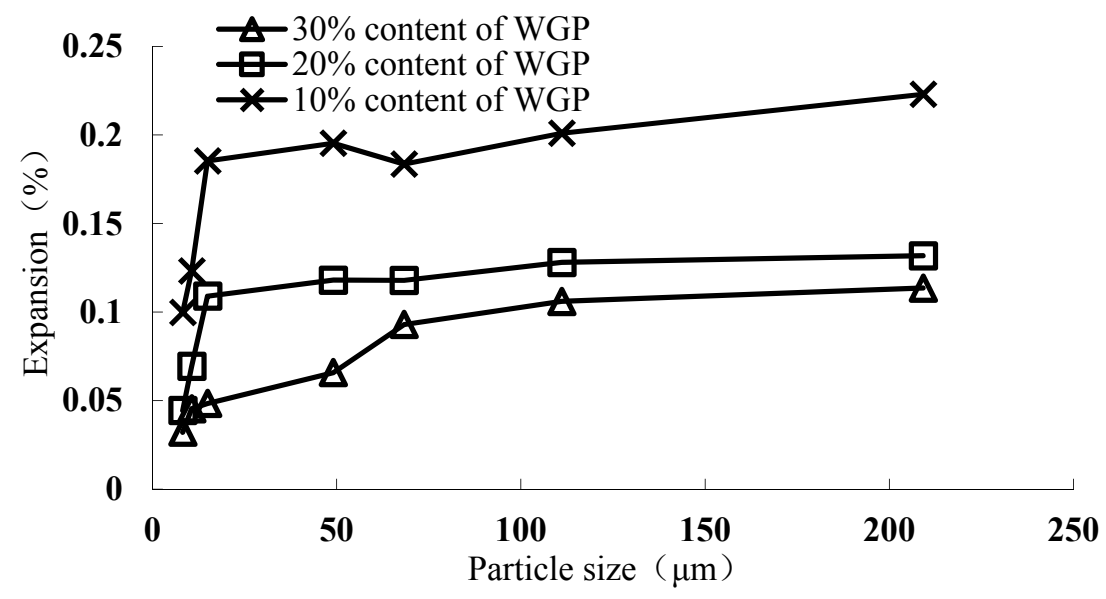

Figure 7. ASR expansion of the mortars containing WGPs with different particle size.

At the same time, it can be drawn from Figure 7 that when the WGP average particle size is less than $14.94 \mu \mathrm{m}$, the inhibitory effect becomes stronger with the decrease of the average particle size. Therefore WGP may have a critical region of inhibitory effect on ASR expansion. In this study, the critical average particle size is $14.94 \mu \mathrm{m}$ (near $15 \mu \mathrm{m}$ ). However, as the fineness classification of WGP is not sufficient, it needs further verification.

Figure 8 is the ASR expansion curves of mortars containing different WGPs with different specific surface area at 14 days. The specific surface area of WGP and the ASR expansion have an anti-correlation. When the material has larger surface area, the reaction area is larger and more atoms on the surface can participate in the reaction according to the atomic effective collision. The greater specific surface area of WGP results in more intense and faster pozzolanic reaction, and thus improves the inhibitory effect on ASR expansion of the system. In addition, the desirable effect can be achieved when WGP content is $10 \%, 20 \%$ and $30 \%$ with its specific surface area larger than 903 , 698 and $97.61 \mathrm{~m}^{2} / \mathrm{kg}$, respectively, according to the interpolation calculation. 


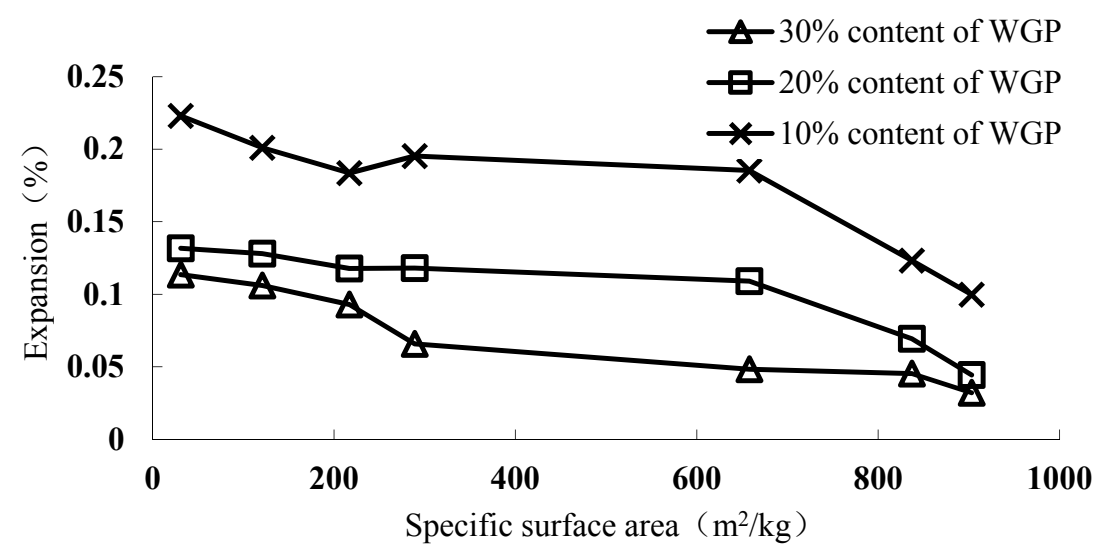

Figure 8. ASR expansion the mortars containing WGP with different specific surface area.

\subsubsection{Effect of Temperature}

In practice, the actual temperature of concrete is different, so it is necessary to consider the effect of curing temperature on the ASR expansion. The ASR expansion under normal $\left(40^{\circ} \mathrm{C}\right)$ and high temperature condition $\left(80^{\circ} \mathrm{C}\right)$ is compared in Figure 9.

As high temperature can improve ASR, the development of ASR expansion under $40{ }^{\circ} \mathrm{C}$ is slower than that under $80^{\circ} \mathrm{C}$, and the expansion at 14 days is maintained at safe levels $(<0.1 \%)$. The chemical reaction rate increases as well as ASR become more obvious along with the increase of curing temperature; meanwhile, higher temperature results in more alkali releasing to the pore solution and increasing ASR risk [25]. Nevertheless, some studies have shown that the high temperature cannot affect the final extent of ASR reaction.

As shown in Table 5, the temperature significantly affects the inhibitory effects of WGP on ASR expansion. As for low WGP content $(<20 \%)$, the higher the temperature, the lower the inhibitory rate. As for high WGP content $(30 \%)$, the result is opposite. Higher temperature also improves the pozzolanic reaction of WGP [26]. The pozzolanic reaction of WGP will reduce ASR, which are two mutually exclusive reactions. The interaction of them determines the ASR expansion rate of the system. When the WGP content is low, the promotion role of temperature on ASR is greater than pozzolanic reaction. However, it is the contrary way when WGP content is high. This is very similar to the role of fly ash. High temperature improves the solubility of fly ash, which promotes pozzolanic reaction, so it can control ASR effectively.

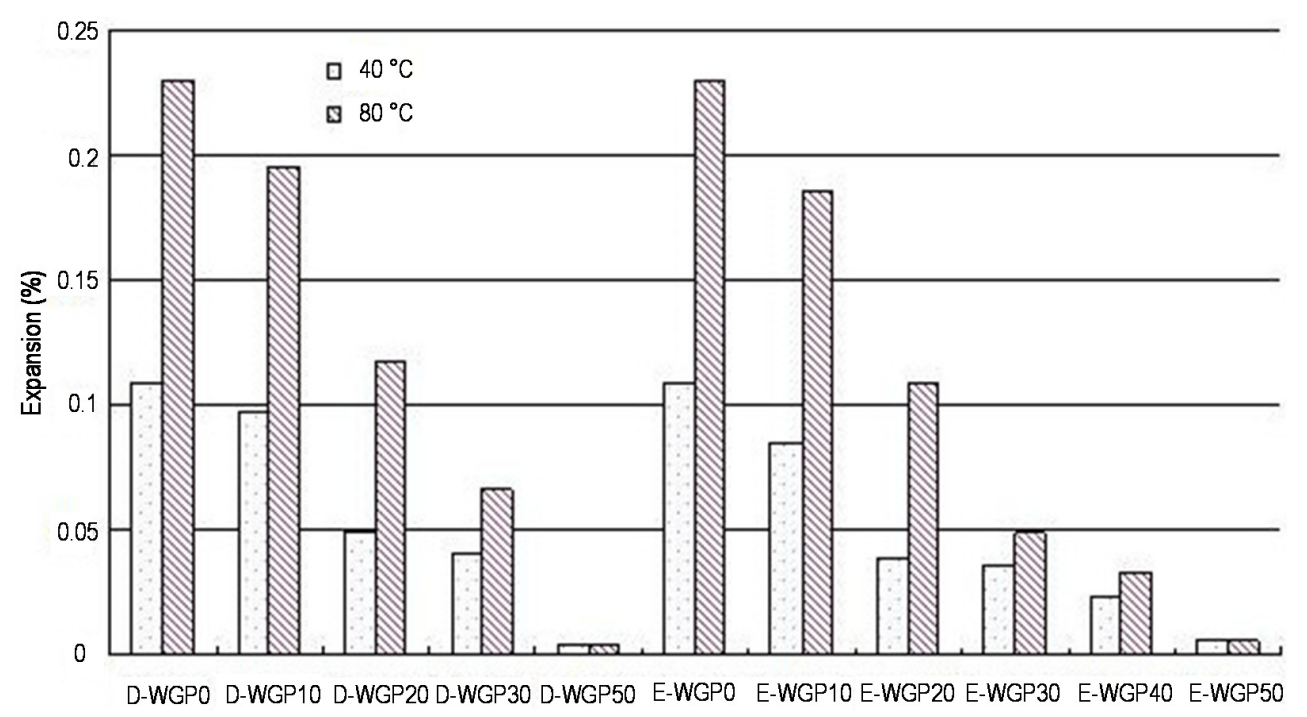

Figure 9. ASR expansion of different mortars under different temperatures at 14 days. 
Table 5. The alkali-silica reaction (ASR) inhibition rate of glass powder at 14 days under different temperature $(\%)$.

\begin{tabular}{ccccccc}
\hline Temperature $\left({ }^{\circ} \mathrm{C}\right)$ & D-WGP0 & D-WGP10 & D-WGP20 & D-WGP30 & D-WGP40 & D-WGP50 \\
\hline 40 & - & 11.010 & 55.050 & 63.300 & - & 63.920 \\
80 & - & 10.070 & 39.590 & 66.320 & - & 98.190 \\
\hline Temperature $\left({ }^{\circ} \mathrm{C}\right)$ & E-WGP0 & E-WGP10 & E-WGP20 & E-WGP30 & E-WGP40 & E-WGP50 \\
\hline 40 & - & 22.020 & 64.220 & 66.970 & 78.900 & 95.410 \\
80 & - & 19.420 & 52.610 & 78.960 & 85.820 & 97.610 \\
\hline
\end{tabular}

\subsubsection{Inhibitory Efficiency of WGP}

According to above analysis, there are two comprehensive factors (i.e., average particle size and content of WGP) controlling the inhibitory effect on ASR expansion. Table 6 lists the inhibitory efficiency of different size and content of WGP in the entire system.

Table 6. The ASR expansion inhibition efficiency with different WGP contents (\%).

\begin{tabular}{llll}
\hline \multirow{2}{*}{ Samples } & \multicolumn{3}{l}{ WGP Content } \\
\cline { 2 - 4 } & $\mathbf{1 0} \%$ & $\mathbf{2 0} \%$ & $\mathbf{3 0 \%}$ \\
\hline A-WGP & 3.04 & 42.71 & 50.65 \\
B-WGP & 12.61 & 44.35 & 53.91 \\
C-WGP & 20.18 & 48.76 & 59.57 \\
D-WGP & 15.07 & 48.70 & 71.39 \\
E-WGP & 19.42 & 52.61 & 78.96 \\
F-WGP & 46.41 & 69.85 & 80.27 \\
G-WGP & 56.61 & 80.71 & 86.03 \\
\hline
\end{tabular}

As can be seen from the above data characteristics, the reasonable law should be studied to provide a reference for the use of WGP. ASR expansion inhibitory rate $Y$ of different WGP has logarithmic relationship with average particle size $D$, linearly related with WGP content $P$, so the model can be established as Equation (1):

$$
Y=\ln \ln (A+B P+C D)
$$

where, $Y$ is the reducing rate of ASR expansion rate compared with the sample without WGP at 14 days, and $Y=1-$ (ASR expansion of the sample with WGP/ASR expansion of the sample without WGP); $A, B$ and $C$ are Parameters; $P$ is the WGP content; and $D$ is the average particle size of WGP.

Using the software of Excel, parameters determined by fitting the data using linear regression, as calculated by Equation (2):

$$
Y=\ln \ln (11.06182-27.1472 P+0.019369 D)
$$

As the fitting case is plotted (Figure 10), the inhibitory efficiency of WGP on ASR expansion has a certain relationship with WGP particle size and content. A rough estimate of ASR expansion can be obtained based on the size and content of WGP, which can provide the basis for the selection of WGP content and particle size. Basically, the smaller the particle size and the higher the WGP content, the higher the inhibitory effect. The simulation calculation shows that fine WGP can not solely control the ASR expansion into a safe range when WGP content is $10 \%$; but ASR expansion rate can be controlled within safe level when WGP content is $20 \%$ and $30 \%$ with its average particle size less than 9.25 and $149.40 \mu \mathrm{m}$, respectively. The calculated results and interpolation calculations have some discrepancy, but the results are relatively more accurate and reliable than the interpolation calculation. 


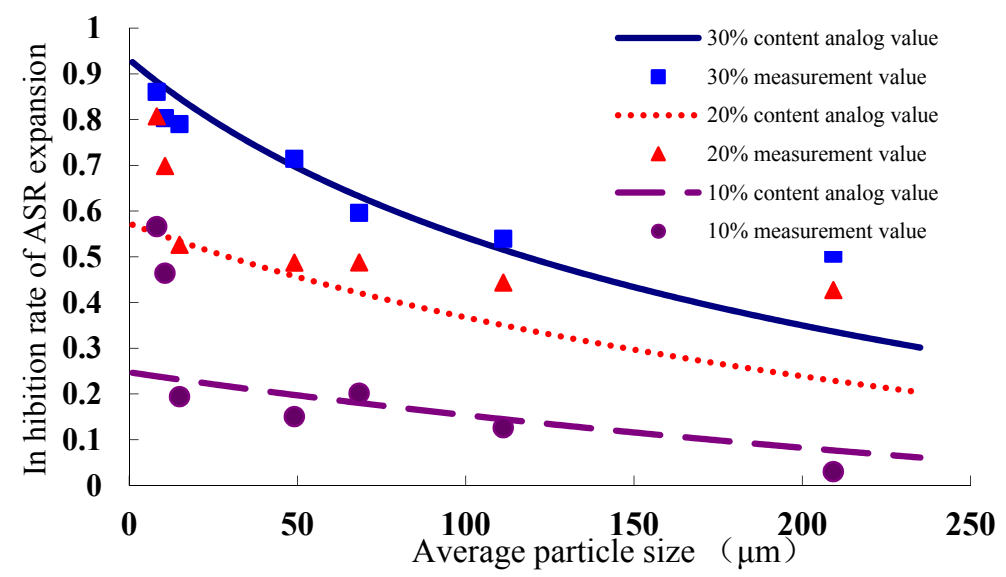

Figure 10. The inhibitory effect of different average particle size on ASR expansion.

From the data characteristics above, there is a high correlation among the specific surface area and content of WGP, and inhibitory rate of ASR expansion, as Equation (3):

$$
Y=a+b P+c S
$$

where $Y$ is the reducing rate of ASR expansion rate compared with the sample without WGP at 14 days, $Y=1-$ (ASR expansion of the sample with WGP/ASR expansion of the sample without WGP); $a, b$ and $c$ are Parameters; $P$ is the WGP content; and $S$ is the specific surface area of WGP.

Based on the linear regression fitting, the parameter can be obtained as Equation (4):

$$
Y=-0.12297+2.195983 P+0.000412 S
$$

As shown in Figure 11, the inhibitory efficiency of WGP on ASR expansion has a linear correlation with the specific surface area and content of WGP. As surface area significantly affects WGP reactivity [27], the higher the surface area and the content of WGP, the better is the inhibitory efficiency. According to the simulation calculation, the ASR expansion can be controlled in a safe range when WGP content is $10 \%, 20 \%$ and $30 \%$ with its specific surface area larger than 1137.40 , 604.37 and $71.34 \mathrm{~m}^{2} / \mathrm{kg}$, respectively.

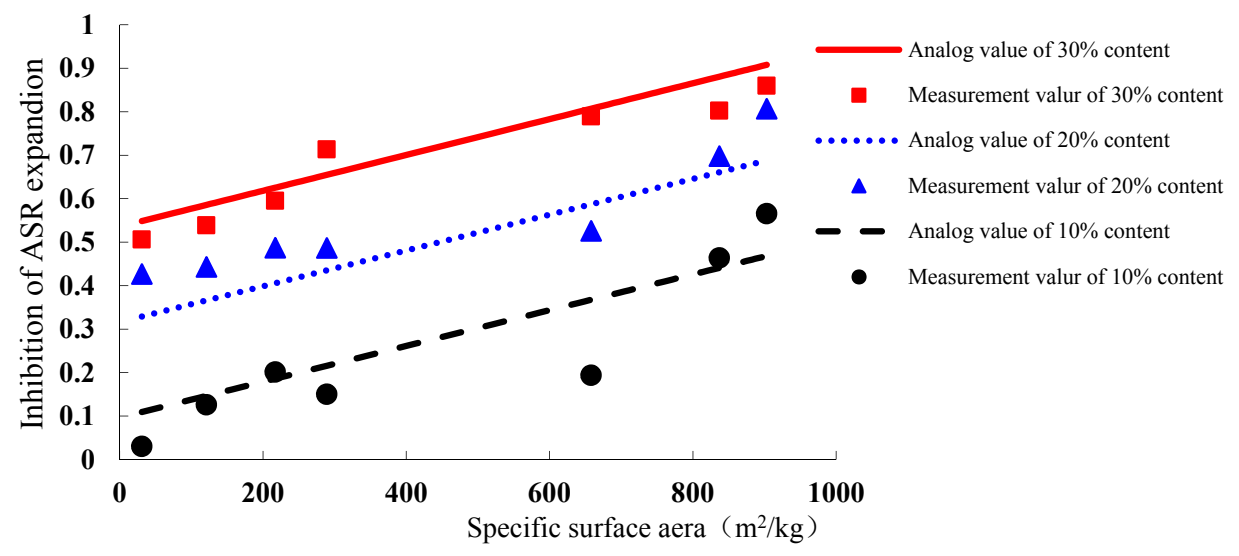

Figure 11. The inhibitory effect of different specific surface area on ASR expansion.

\subsection{Microstructural Study}

Figure 12 is the SEM images of different samples. The ASR ring around the large glass aggregate particle and the microcrack could be found easily in Figure 12a, which shows the serious ASR expansion has taken place and caused cracking in the mortar. It is consistent with the results of 
the macro test. Compared with Figure 12a, there is no ASR ring or microcrack around the large glass aggregate, but it is webbed C-S-H in the sample containing 30\% WGP (Figure 12b); the C-S-H gel may be generated by the pozzolanic reaction of WGP around the WG aggregate. The C-S-H may react with the $\mathrm{SiO}_{2}$ again to generate $\mathrm{C}-\mathrm{S}-\mathrm{H}$ with low $\mathrm{Ca} / \mathrm{Si}$ ratio. ASR is a slow process that is later than the pozzolanic reaction, it generates $\mathrm{C}-\mathrm{S}-\mathrm{H}$ wrapping of the aggregate to improve the cementing property between the aggregate and the surroundings, and prevents ASR to some degree.

The $\mathrm{Ca} / \mathrm{Si}$ ratio of C-S-H gel in the mortar with WGP is low and is close to 1 (Figure 13d). $\mathrm{C}-\mathrm{S}-\mathrm{H}$ gel with a low $\mathrm{Ca} / \mathrm{Si}$ ratio is tobermorite whose gel strength is relatively high. It is the result of the pozzolanic reaction between reactive $\mathrm{SiO}_{2}$ of WGP and $\mathrm{Ca}(\mathrm{OH})_{2}$ of the initial cement hydration $[28,29]$. Additionally, excessive reactive $\mathrm{SiO}_{2}$ continues reacting with the $\mathrm{C}-\mathrm{S}-\mathrm{H}$ gel with high $\mathrm{Ca} / \mathrm{Si}$ ratio to form $\mathrm{C}-\mathrm{S}-\mathrm{H}$ gel with low $\mathrm{Ca} / \mathrm{Si}$ ratio. Besides, Figure 13d shows that the gel contains sodium, which is the chemical compositions of WGP. C-S-H gel with low $\mathrm{Ca} / \mathrm{Si}$ ratio adsorbs the alkali metals strongly, which verifies that WGP preferentially reacts with the $\mathrm{Ca}(\mathrm{OH})_{2}$ to generate $\mathrm{C}-\mathrm{S}-\mathrm{H}$ gel and avoid ASR.

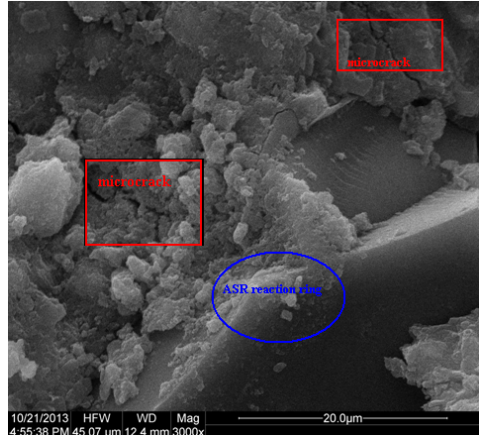

(a)

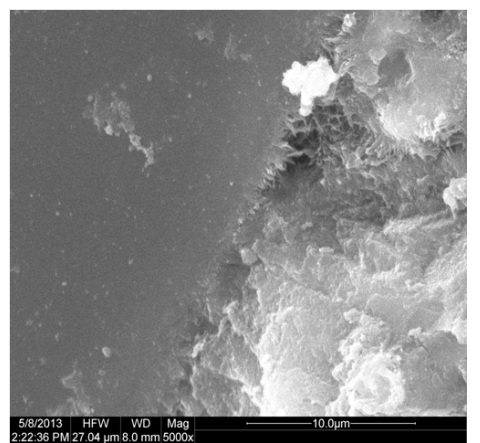

(b)

Figure 12. Scanning electron microscopy (SEM) images of mortars (a) without and (b) with $30 \%$ WGP.

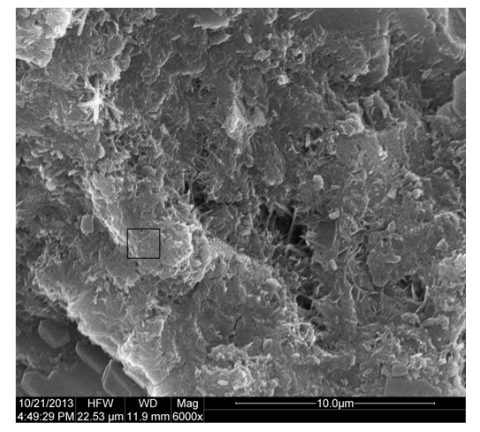

(a)

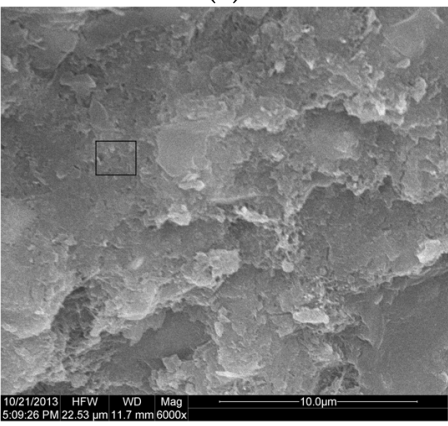

(c)

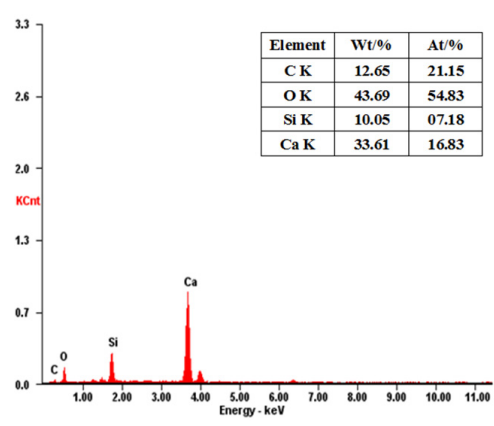

(b)

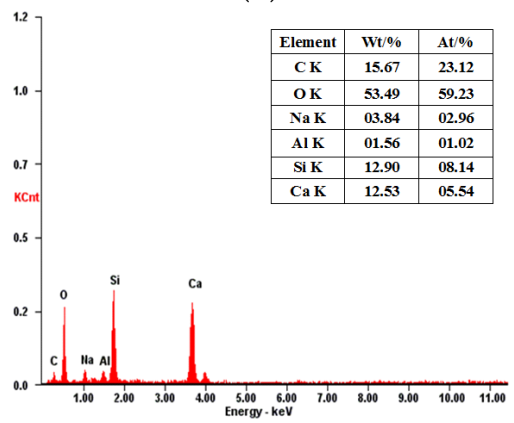

(d)

Figure 13. SEM and EDX results of mortars without and with 30\% WGP: (a) SEM without WGP; (b) EDX without WGP; (c) SEM with WGP; and (d) EDX with WGP. 


\section{Conclusions}

(1) WG aggregate has high alkali reactivity. The ASR expansion increases with the increase of the replacement ratio of glass aggregate, and reaches the maximum values at $90 \%$ replacement ratio.

(2) WGP can greatly reduce the ASR expansion induced by glass aggregate. The ASR expansion decreases with the increase of the content and fineness of WGP. When WGP size is less than $209.2 \mu \mathrm{m}$, it will add no ASR expansion and, meanwhile, it has a certain inhibitory effect on ASR expansion.

(3) The specific surface area of WGP and the ASR expansion have an anti-correlation, which leads the pozzolanic reaction more intense and faster and higher inhibitory effect on ASR expansion. The ASR expansion can be controlled in a safe range when WGP content is $10 \%, 20 \%$ and $30 \%$ with its specific surface area greater than $1137.40,604.37$ and $71.34 \mathrm{~m}^{2} / \mathrm{kg}$, respectively, or with low average particle size according to the calculation.

(4) Higher temperature can promote both the pozzolanic reaction and ASR, and the inhibitory rate increases under high temperature for low WGP content $(<20 \%)$, but decreases for high WGP content (30\%).

(5) Microstructural study confirms the macro testing. There will be ASR reaction ring around the large glass aggregate particle and the microcrack in the mortar without WGP, but C-S-H gel with low Ca/Si ratio and no ASR will appear in the mortar with WGP.

Acknowledgments: This Project is funded by the National Natural Science Foundation of China (51208391).

Author Contributions: Shuhua Liu and Shu Wang conceived and designed the experiments; Shu Wang and Wan Tang performed the experiments; Ningning $\mathrm{Hu}$ and Jianpeng Wei analyzed the data; Shuhua Liu contributed reagents/materials/analysis tools; Shuhua Liu and Shu Wang wrote the paper.

Conflicts of Interest: The authors declare no conflict of interest.

\section{References}

1. Mukesh, C. Bulk engineering and durability properties of washed glass sand concrete. Constr. Build. Mater. 2009, 23, 1078-1083.

2. Schwarz, N.; Neithalath, N. Influence of a fine glass powder on cement hydration, Comparison to fly ash and modeling the degree of hydration. Cem. Concr. Res. 2008, 38, 429-436. [CrossRef]

3. Wang, H.Y.; Huang, W.L. Durability of self-consolidating concrete using waste LCD glass. Constr. Build. Mater. 2010, 24, 1008-1013. [CrossRef]

4. Wang, H.Y.; Huang, W.L. A study on the properties of fresh self-consolidating glass concrete. Constr. Build. Mater. 2010, 24, 619-624. [CrossRef]

5. Kou, S.C.; Poon, C.S. Properties of self-compacting concrete prepared with recycled glass aggregate. Cem. Concr. Compos. 2009, 31, 107-113. [CrossRef]

6. $\quad$ Lin, K.L.; Wang, N.F.; Shie, L.; Lee, T.C.; Lee, C. Elucidating the hydration properties of paste containing thin film transistor liquid crystal display waste glass. J. Hazard. Mater. 2008, 159, 471-475. [CrossRef] [PubMed]

7. Lisa, M.; Federico, E.B. Waste Glass-A Supplementary Cementitious Material; McMaster University: Hamilton, ON, Canada, 2013.

8. Mirzahosseini, M.R. Glass Cullet as a New Supplementary Cementitious Material (SCM). Ph.D. Thesis, Kansas State University, Manhattan, KS, USA, March 2014.

9. China Standards Publication. Sand for construction; GB/T14684-2001; China Building Industry Press: Beijing, China, 2001.

10. American Society for Testing Materials. Standard Test Method for Potential Alkali Reactivity of Cement-Aggregate Combinations (Mortar-Bar Method); ASTM C227-10; ASTM International: West Conshohocken, PA, USA, 2010.

11. American Society for Testing Materials. Standard Test Method for Potential Alkali Reactivity of Aggregates (Mortar-Bar Method); ASTM C1260-14; ASTM International: West Conshohocken, PA, USA, 2014.

12. Tang, W.D. Experimental research on the worst point effect of hydraulic concrete alkali aggregate reaction. Concrete 2009, 59, 35-37. 
13. Ling, T.C.; Poon, C.S. Utilization of recycled glass derived from cathode ray tube glass as fine aggregate in cement mortar. J. Hazard. Mater. 2011, 192, 451-456. [CrossRef] [PubMed]

14. Xiong, Q. The Testing Method and Suppressing Measure of Alkali Aggregate Reaction. Master's Thesis, Southwest Jiaotong University, Chengdu, China, April 2006.

15. Jiang, B.; Fan, Y.C.; Jin, S.X. Glascrete-concrete with glass aggregate. J. Shijiazhuang Railw. Inst. 2001, 14, 50-54.

16. Zhang, X.G.; Wang, C.B. Effect of temperature on length measurement method of alkali aggregate reaction. Eng. Constr. 2008, 40, 36-37.

17. Liu, S.H.; Xie, G.S.; Wang, S. Effect of curing temperature on hydration properties of waste glass powder in cement-based materials. J. Therm. Anal. Calorim. 2015, 119, 47-55. [CrossRef]

18. Lee, G.; Ling, T.C.; Wong, Y.L.; Poon, C.S. Effects of crushed glass cullet sizes, casting methods and pozzolanic materials on ASR of concrete blocks. Constr. Build. Mater. 2011, 25, 2611-2618. [CrossRef]

19. Rajabipour, F.; Maraghechi, H.; Fischer, G. Investigating the alkali silica reaction of recycled glass aggregates in concrete materials. J. Mater. Civil Eng. 2010, 22, 1201-1208. [CrossRef]

20. Saccani, A.; Bignozzi, M.C. ASR expansion behavior of recycled glass fine aggregates in concrete. Cem. Concr. Res. 2010, 40, 531-536. [CrossRef]

21. Idir, R.; Cyr, M.; Tagnit-Hamou, A. Use of fine glass as ASR inhibitor in glass aggregate mortars. Constr. Build. Mater. 2010, 24, 1309-1312. [CrossRef]

22. Mirzahosseini, M.R.; Riding, K.A. Influence of different particle sizes on reactivity of finely ground glass as new supplementary cementitious material (SCM). Ceme. Concr. Compos. 2015, 56, 95-105. [CrossRef]

23. Nassar, R.; Soroushian, P. Strength and durability of recycled aggregate concrete containing milled glass as partial replacement for cement. Constr. Build. Mater. 2012, 29, 368-377. [CrossRef]

24. Shayan, A.; Xu, A.M. Performance of glass powder as a pozzolanic material in concrete: A field trial on concrete slabs. Cem. Concr. Res. 2006, 36, 457-468. [CrossRef]

25. Liu, C.X.; Chen, G.X.; Ji, G.J.; Wang, X.J. The effect of temperature on alkali-silica reaction. China Concr. Cem. Prod. 2012, 191, 1-4.

26. Mirzahosseini, M.R.; Riding, K.A. Influence of curing temperature and glass type on the pozzolanic reactivity of glass powder. Cem. Concr. Res. 2014, 58, 103-111. [CrossRef]

27. Mirzahosseini, M.; Riding, K. Effect of combined glass particles on hydration in cementitious systems. J. Mater. Civil Eng. 2015, 27, 401-419. [CrossRef]

28. Yan, P.Y.; Mi, G.D.; Wang, Q. A comparison of early hydration properties of cement-steel slag binder and cement-limestone powder binder. J. Therm. Anal. Calorim. 2014, 115, 193-200. [CrossRef]

29. Liu, S.H.; Xie, G.S.; Wang, S. Effect of glass powder on microstructure of cement pastes. Adv. Cem. Res. 2015, 27, 259-267. [CrossRef]

(C) 2015 by the authors; licensee MDPI, Basel, Switzerland. This article is an open access article distributed under the terms and conditions of the Creative Commons by Attribution (CC-BY) license (http:/ / creativecommons.org/licenses/by/4.0/). 